\title{
OPTICAL AND ELECTRICAL PROPERTIES OF BULK GaSb AND AlGaSb ${ }^{\dagger}$
}

\author{
P. KACZOR, Z.R. ŻYTKIEWICZ, D. DoBosz AND Z. KALIŃSKI \\ Institute of Physics, Polish Academy of Sciences \\ Al. Lotników 32/46, 02-668 Warszawa, Poland
}

\begin{abstract}
Optical measurements of bulk GaSb:S reveal the structure of the lattice two phonon absorption and acceptor-valence band transitions. A sulphur related local vibrational modes and several bands related to the optical transitions from the ground state of the acceptor level are observed. A comparison of transport and optical measurements for GaSb:Te and AlGaSb:Te shows that in the alloy it is easier to obtain high concentrations of the electrically active Te impurity.
\end{abstract}

PACS numbers: $61.72 . \mathrm{Vv}, 63.20 . \mathrm{Pw}, 71.55 . \mathrm{Eq}$

Recently, GaSb and its alloys have got an increasing importance as materials for optoelectronics. Heterostructure lasers for 1.5-2 $\mu \mathrm{m}$ wavelength range and photodetectors consisting of $\mathrm{GaSb} / \mathrm{AlGaSb}$ or $\mathrm{GaSb} / \mathrm{AlGaAsSb}$ layers are extensively developed [1]. It is therefore a bit surprising how little is known about optical properties of $\mathrm{GaSb}$ or $\mathrm{AlGaSb}$ compared to, e.g., GaAs or AlGaAs. For example, there have been no optical measurements of lattice or local vibrational modes carried out since the low resolution measurements in the fifties [2].

We hope that the unique growth technology of liquid phase electroepitaxy (LPEE) will help to bridge over this large gap between research and application especially when alloys are concerned. LPEE enabled us to obtain a set of thick (400-900 $\mu \mathrm{m})$ samples of GaSb and AlGaSb with a high crystal quality and compositional uniformity. Such thick and large area samples are not attainable with the use of nonequilibrium growth techniques such as molecular beam epitaxy or even traditional Czochralski growth.

In our paper we present optical measurements of $\mathrm{GaSb}$ and AlGaSb doped with sulphur and tellurium carried out in wide spectral range $\left(200-5000 \mathrm{~cm}^{-1}\right)$. A two phonon mode lattice absorption has been measured for GaSb and a new classification of phonon frequencies is attempted. In compensated $p$-type GaSb:S samples a strong broad absorption band is observed. It is tentatively attributed to the photoionization of the second charge state of the native double acceptor.

${ }^{\dagger}$ This work has been supported by the State Committee for Scientific Research (Republic of Poland) grants No. 2 P302 11705 and 223639023. 
In our study the GaSb:S bulk samples were grown by two different techniques: Czochralski and LPEE. The carrier concentration ranges from $p=$ $1 \times 10^{17} \mathrm{~cm}^{-3}$ to $n=2 \times 10^{16} \mathrm{~cm}^{-3}$ at room temperature. It was not possible to obtain higher $n$-type carrier concentrations in GaSb:S although dopings either with very high amounts of sulphur or $\mathrm{Ga}_{2} \mathrm{~S}$ were attempted. The carrier mobilities are of the order of $300 \mathrm{~cm}^{2} /(\mathrm{V} \mathrm{s})$ at room temperature and $900 \mathrm{~cm}^{2} /(\mathrm{V} \mathrm{s})$ at $77 \mathrm{~K}$ in either $p$ or $n$-type samples. The free carrier concentrations fall by one order of magnitude at lower temperatures (10-77 K) regardless of the room temperature initial carrier concentration or the type of conductivity.

Due to this free carrier "freeze out" process at lower temperatures the GaSb:S samples are perfectly suited for optical measurements. The absorption coefficient of GaSb:S was measured in the $200-5000 \mathrm{~cm}^{-1}$ wave number range with FTIR Bomem DA3 spectrometer at temperatures between 10 and $300 \mathrm{~K}$ and resolution of $2 \mathrm{~cm}^{-1}$. Interesting features appear below $1000 \mathrm{~cm}^{-1}$ (Fig. 1). In both $n$-type and $p$-type samples strong lattice absorption bands can be observed in the 200-480 $\mathrm{cm}^{-1}$ spectral region. Their temperature dependencies suggest that all peaks above the strong restrahlen band centered at $230 \mathrm{~cm}^{-1}$ can be attributed to several two phonon summation bands. Due to the sufficiently high spectral resolution it was possible to reveal the detailed structure of this absorption. The results are summarized in Table.

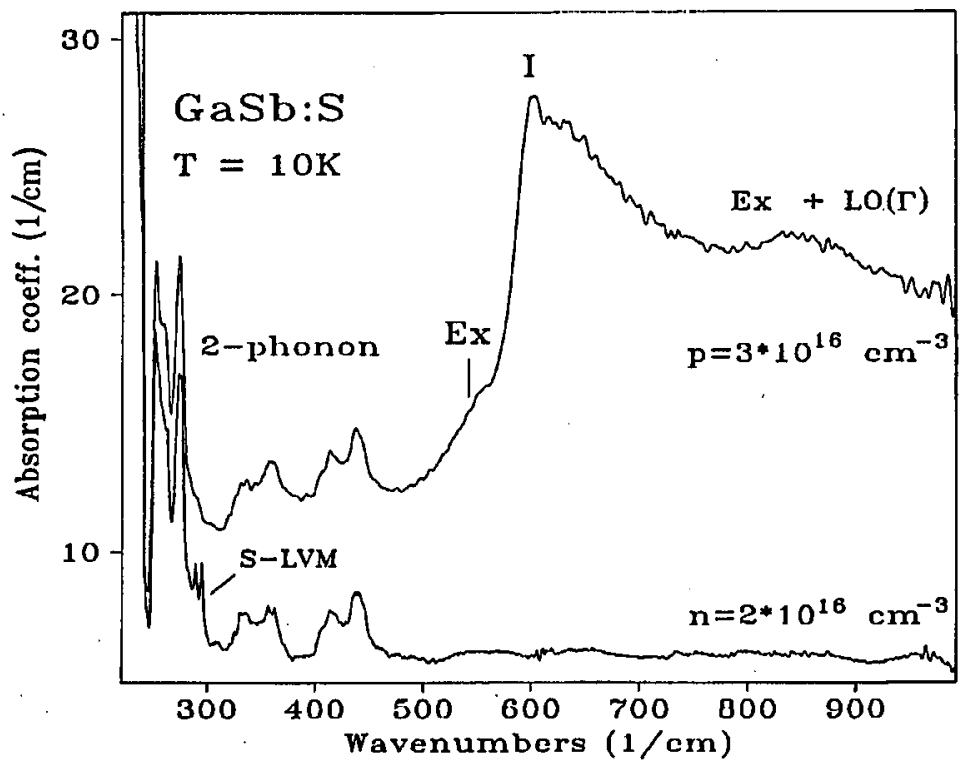

Fig. 1. Absorption bands in GaSb:S. In the $n$ - and $p$-type samples two phonon absorption is seen. In the $p$-type sample acceptor optical transitions to the excited states (Ex), a photoionization band (I) and transition to a virtual state $(\mathrm{Ex}+\mathrm{LO}(\Gamma))$ are observed. In the $n$-type sample the sulphur related LVM appears. 
Assignment of the two phonon absorption bands in GaSb:S.

TABLE

\begin{tabular}{|c|c|c|c|c|c|c|c|}
\hline $\begin{array}{c}\text { IR-Exp. } \\
\text { This } \\
\text { work }\end{array}$ & \multicolumn{2}{|c|}{$\begin{array}{l}\text { Assignment } \\
\text { This work }\end{array}$} & \multicolumn{2}{|c|}{$\begin{array}{l}\text { Assignment acc. } \\
\text { to neutron scatt. } \\
\text { data [4] }\end{array}$} & \multirow[t]{2}{*}{$\begin{array}{l}\text { Phonons } \\
\text { at critical } \\
\text { points } \\
\mathrm{TO}(\mathrm{X})\end{array}$} & \multirow{2}{*}{$\begin{array}{l}\text { This } \\
\text { work }\end{array}$} & \multirow{2}{*}{$\begin{array}{c}\text { Neutron } \\
\text { scatt. } \\
{[4]} \\
212.0\end{array}$} \\
\hline 252.3 & 252.0 & $\mathrm{LO}(\mathrm{L})+\mathrm{TA}(\mathrm{L})$ & 250.6 & $\mathrm{LO}(\mathrm{L})+\mathrm{TA}(\mathrm{L})$ & & & \\
\hline 255.3 & & & & & $\mathrm{LO}(\mathrm{X})$ & 216.5 & 211.7 \\
\hline 260.0 & 260.0 & 2LA(L) & 261.6 & $\mathrm{TO}(\mathrm{L})+\mathrm{TA}(\mathrm{L})$ & $\mathrm{TA}(\mathrm{X})$ & 56.0 & 56.6 \\
\hline 263.0 & 262.0 & $\mathrm{TO}(\mathrm{L})+\mathrm{TA}(\mathrm{L})$ & & & $\mathrm{LA}(\mathrm{X})$ & 141.0 & 166.3 \\
\hline 273.0 & 272.5 & $\mathrm{LO}(\mathrm{X})+\mathrm{TA}(\mathrm{X})$ & 268.3 & $\mathrm{LO}(\mathrm{X})+\mathrm{TA}(\mathrm{X})$ & TO(L) & 213.0 & 216.0 \\
\hline \multirow[t]{2}{*}{276.0} & 276.5 & $\mathrm{TO}(\mathrm{X})+\mathrm{TA}(\mathrm{X})$ & 268.6 & $\mathrm{TO}(\mathrm{X})+\mathrm{TA}(\mathrm{X})$ & LO(L) & 203.0 & 205.0 \\
\hline & 282.0 & 2LA(X) forb. & 306.6 & $2 \mathrm{LA}(\mathrm{L})$ & $\operatorname{TA}(\mathrm{L})$ & 49.0 & 45.6 \\
\hline 330.0 & & & 332.6 & $2 L A(X)$ forb. & $\mathrm{LA}(\mathrm{L})$ & 130.0 & 153.3 \\
\hline 334.0 & 333.0 & $\mathrm{LO}(\mathrm{L})+\mathrm{LA}(\mathrm{L})$ & & & & & \\
\hline \multicolumn{8}{|l|}{337.0} \\
\hline $338-350$ & 343.0 & $\mathrm{TO}(\mathrm{L})+\mathrm{LA}(\mathrm{L})$ & & & & & \\
\hline 356.0 & 357.5 & $\mathrm{LO}(\mathrm{X})+\mathrm{LA}(\mathrm{X})$ & 358.3 & $\mathrm{LO}(\mathrm{L})+\mathrm{LA}(\mathrm{L})$ & & & \\
\hline 362.0 & 361.5 & $\mathrm{TO}(\mathrm{X})+\mathrm{LA}(\mathrm{X})$ & 369.3 & $\mathrm{TO}(\mathrm{L})+\mathrm{LA}(\mathrm{L})$ & & & \\
\hline 406.5 & 406 & $2 \mathrm{LO}(\mathrm{L})$ & & & & & \\
\hline 413.0 & & & 410.0 & $2 \mathrm{LO}(\mathrm{L})$ & & & \\
\hline 418.0 & 416 & $\mathrm{TO}(\mathrm{L})+\mathrm{LO}(\mathrm{L})$ & 421.0 & $\mathrm{TO}(\mathrm{L})+\mathrm{LO}(\mathrm{L})$ & & & \\
\hline \multirow[t]{3}{*}{$420-433$} & 426.0 & $2 \mathrm{TO}(\mathrm{L})$ & 423.4 & 2LO(X) forb. & & & \\
\hline & 433.0 & $2 \mathrm{LO}(\mathrm{X})$ forb. & 423.7 & $\mathrm{TO}(\mathrm{X})+\mathrm{LO}(\mathrm{X})$ & & & \\
\hline & & & 424.0 & $2 \mathrm{TO}(\mathrm{X})$ & & & \\
\hline 435.0 & 437.0 & $\mathrm{TO}(\mathrm{X})+\mathrm{LO}(\mathrm{X})$ & 432 & $2 \mathrm{TO}(\mathrm{L})$ & & & \\
\hline 440.0 & 441.0 & $2 \mathrm{TO}(\mathrm{X})$ & & & & & \\
\hline
\end{tabular}

If an identification of the bands is attempted, according to phonon Brillouin zone critical point analysis [3], one obtains the $\mathrm{LA}(\mathrm{X})$ and $\mathrm{LA}(\mathrm{L})$ phonon frequencies considerably lower than those obtained from the neutron diffraction experiments (i.e. 141 vs. $166 \mathrm{~cm}^{-1}$ and 131 vs. $155 \mathrm{~cm}^{-1}$, respectively) [4]. Therefore, it seems to us that more detailed theoretical calculations are needed as the two phonon density of states does not necessarily originate from simple combinations of the one phonon densities at critical points but from regions of lower symmetry [5].

In the $n$-type and in the strongly compensated $p$-type GaSb:S two peaks at $289 \mathrm{~cm}^{-1}$ and $295 \mathrm{~cm}^{-1}$ appear. The strength of these peaks scales with the sulphur content. According to their temperature dependence they are attributed to local vibrational modes (LVM) of a sulphur related defect of probably $C_{s}$ symmetry. To our knowledge it is the first observation of group VI element LVM in GaSb.

Above $500 \mathrm{~cm}^{-1}$ there is a strong electronic absorption in the $p$-type samples, which we attribute to a photoionization of the second charge state level of the $\mathrm{Gasb}_{\mathrm{Sb}}$ native double acceptor [6]. The structure seen on this broad band is similar to other acceptor photoionization bands seen in III-V compounds [7]. The maximum at $602 \mathrm{~cm}^{-1}$ corresponds to the photoionization itself. The small bump $\left(\nu=547 \mathrm{~cm}^{-1}\right)$ at the maximum lower energy side can be related to a strongly 
concentration broadened excited state transition. The binding energy of the acceptor centre estimated from the photoionization band should be of the order of $75 \mathrm{meV}$ which is in agreement with the Hall data [6].

At the higher energy side of the photoionization maximum there is another band $\left(\nu \approx 850 \mathrm{~cm}^{-1}\right)$ which, similarly to the acceptor absorption in GaAs or Ge [7], can be tentatively attributed to either a transition to the spin-orbit split valence band maximum or a virtual state consisting of the excited acceptor state plus the $\mathrm{LO}(\Gamma)$ phonon. The spin-orbit splitting in GaSb estimated from the first transition would be of the order of $30 \mathrm{meV}$ which is quite improbable for an antimony-based compound [8]. Thus, the second transition has to be chosen for the origin of the $850 \mathrm{~cm}^{-1}$ band.

Tellurium incorporates into $\mathrm{GaSb}$ much easier than sulphur. The $\mathrm{GaSb}: \mathrm{Te}$ and $\mathrm{Al}_{0.2} \mathrm{Ga}_{0.8} \mathrm{Sb}$ :Te crystals are $n$-type and have the dopant concentrations in the range of $5 \times 10^{17}-2 \times 10^{18} \mathrm{~cm}^{-3}$. The carrier mobilities are orders of magnitude better than in the case of GaSb:S. We obtained for GaSb:Te $\mu_{\mathrm{H}}=5300 \mathrm{~cm}^{2} /(\mathrm{V} \mathrm{s})$ at $T=77 \mathrm{~K}$ and $3400 \mathrm{~cm}^{2} /(\mathrm{V} \mathrm{s})$ at $T=300 \mathrm{~K}$. If tellurium is introduced into the $\mathrm{GaSb}$ and $\mathrm{AlGaSb}$ solutions in the same amounts then the concentration of electrically active centres is larger by almost an order of magnitude in the latter case. Probably the crystal alloying process reduces the native acceptor concentration in the compound. On the other hand, it is very difficult to obtain compensated or moderately doped GaSb:Te or AlGaSb:Te. In these samples the free carrier absorption makes impossible to carry out any optical measurements at wave numbers lower than $1000 \mathrm{~cm}^{-1}$.

In conclusion, the new results on a relatively "unknown" III-V compound - GaSb are obtained. The two phonon absorption frequencies are measured with the resolution which makes possible the exact theoretical line assignment. Several optical transitions from the ground state of the $\mathrm{GaSb}_{\mathrm{Sb}} \mathrm{A}^{-} / \mathrm{A}^{--}$-level are observed. LVM of a group VI element-related defect in GaSb are reported for the first time.

\section{Acknowledgments}

We are very grateful to Prof. Leszek Dobaczewski for critical reading of the manuscript and helpful discussions.

\section{References}

[1] Y. Ohmori, Y. Suzuki, H. Okamoto, Jpn. J. Appl. Phys. 24, L657 (1985); T. Miyazawa, S. Tarucha, Y. Ohmori, Y. Suzuki, H. Okamoto, Jpn. J. Appl. Phys. 25, L200 (1986).

[2] H.J. Hrostowski, C.S. Fuller, J. Phys. Chem. Solids 4, 155 (1958).

[3] J.L. Birman, Phys. Rev. 131, 1489 (1963).

[4] M.K. Farr, J.G. Taylor, S. K. Sinha, Phys. Rev. B 11, 1587 (1975).

[5] E.S. Koteles, W.R. Datars, Can. J. Phys. 54, 1676 (1976).

[6] K. Nakashima, Jpn. J. Appl. Phys. 20, 1085 (1981).

[7] R.A. Chapman, W.G. Hutchinson, Phys. Rev. Lett. 18, 443 (1967).

[8] J.R. Chelikowsky, M.L. Cohen, Phys. Rev. B 14, 556 (1976). 